\title{
THE EFFECTS OF FRAGRANCED MICROCAPSULES APPLICATION ON THE PHYSICAL AND PRINT QUALITY CHARACTERISTICS OF THE PRINTS
}

\author{
Rastko Milošević ${ }^{1}$ (D), Nemanja Kašiković ${ }^{1}$ (D), Živko Pavlović ${ }^{1}$ (D), Saša Petrović ${ }^{1}$ (D), \\ Dragan Kukuruzović ${ }^{2}$ (D), Raša Urbas ${ }^{3}$ (D) \\ ${ }^{1}$ University of Novi Sad, Faculty of Technical Sciences, Department of Graphic Engineering and \\ Design, Novi Sad, Serbia \\ ${ }^{2}$ University of Novi Sad, Faculty of Technical Sciences, Department for Production Engineering, \\ Novi Sad, Serbia \\ ${ }^{3}$ University of Ljubljana, Faculty of Natural Sciences and Engineering, Department of Textiles, \\ Graphic Arts and Design, Ljubljana, Slovenia
}

\begin{abstract}
Today, various coatings are used in the printing industry, which give the printed product various additional features such as functional, decorative and protective properties. As a coating, fragrant microcapsules can be applied in combination with a printing ink or varnish to provide printed products with added value. The functionality of the applied fragranced microcapsules is initiated and achieved by rubbing the applied coating surface, whereby the microcapsules burst open and release the encapsulated active ingredient, the fragrance. In this paper the effects of the applied fragrance microcapsules (in the form of coating) on the print quality and the physical properties of the coated prints are investigated. Performed AFM and print quality analyses of the functional coatings produced showed that the applied fragrance microcapsules and their different concentrations significantly influence both the physical and print quality properties of the prints.
\end{abstract}

Keywords: fragranced microcapsules, functional coatings, print gloss, surface roughness

\section{INTRODUCTION}

The printing industry faces immense challenges and a demand for new, innovative and value-added print products that can deliver both customer benefits and higher profits for printers. One of the ways to create innovative, value-added printed products is the use of scents using fragranced microcapsules (Milošević, 2019; American Inks and Coatings, n.d.). In order to decorate, protect or give a new functionality to the printed product, different types of coatings are used today, which may contain different materials that enable certain properties, e.g. fragrant microcapsules (Milošević, 2019; Ghosh, 2006). Microcapsules are tiny particles that have a very regular, spherical shape and usually consist of two main parts: the core encapsulated active material, and the shell - an outer part that protects the core (Ghosh, 2006). The fragrant microcapsules encapsulating scents, are mechanically activated by a frictional movement (ie. rubbing motion, application of pressure and shear force) under which the shell of the microcapsules bursts and releases the encapsulated fragrance. Numerous types of microcapsules encapsulate different active ingredients (ie. agents) and have different functionalities and can be incorporated into printing substrates or applied to their surface by various printing or non-printing techniques (Milošević, 2019; Rodrigues et al, 2009; Goetzendorf-Grabowska et al 2004; Goetzendorf-Grabowska et al, 2008; Urbas et al, 2017). Coated prints with fragrant microcapsules have a new functionality, but as a negative effect, the applied coating layer changes its important physical and optical properties, resulting in higher surface roughness and thickness of the prints and a change in print quality characteristics. For this reason, it is important to analyze the physical and optical properties of the coated prints with different fragranced microcapsules mass concentrations, and to determine the extent to which they differ from the original prints (uncoated samples) (Milošević, 2019, Urbas et al, 2017).

This research aims to investigate the influence of applied coatings with fragrant microcapsules on surface roughness as a physical property and the print gloss characteristics of the prints. Performed AFM and print gloss analyses of the produced functional coatings (using an automated coating technique and different mass concentrations of the fragrant microcapsules) showed that the coating process significantly influences both the surface roughness and the print gloss characteristics of the prints. 


\section{METHODS}

For substrate material that was to be printed and coated in the experiment, a matt coated paper (GardaMatt Art, Lecta, Spain) with the following basic properties was used: base weight $130 \mathrm{~g} / \mathrm{m}^{2}$, specific volume $0.85 \mathrm{~cm}^{3} / \mathrm{g}$, thickness $111 \mu \mathrm{m}$ and CIE whiteness 121.3. First, selected substrates were printed with cyan process ink (Diatone ${ }^{\circledR}$ PREMIUM+, Sakata inx, Japan) using sheetfed offset technology (Performa 74, KBA, Germany). The printed samples were coated only with water-based varnish and a mixture of varnish and various mass concentrations of fragrant microcapsules in water suspension. The fragranced microcapsules used were monocore microcapsules produced by a modified "in situ" polymerization method, in which a combination of several essential oils was encapsulated with the fragrances of rosemary, lavender and sage, while the microcapsule shell consisted of partially methylated trimethylol melamine (Melamin, Slovenia) (Šumiga, 2013; Milošević et al, 2017). Water-based printing varnish selected for the coating process of the prints was made of an acrylic emulsion (without the polyethylene wax) and is generally used to protect the prints (Cinkarna Celje, Slovenia). Fragranced microcapsules were premixed with the water-based varnish in three different mass concentrations of $0 \%, 1 \%, 7 \%$. For the coating process the automatic coating technique (K303 Multi Coater, RK PrintCoat Instruments Ltd, UK) with the following process parameter settings was used: coating rod 2 (wet printing thickness $12 \mu \mathrm{m}$ ), diameter of wire for coating rod $0.15 \mathrm{~mm}$ and coating speed $8 \mathrm{~m} / \mathrm{min}$. Coated prints were then air dried for 24 hours at room temperature $\left(25^{\circ} \mathrm{C}, 55 \% \mathrm{RH}\right.$; LED Termohigrometar, RWT-291B, Realwayto, China).

The characterization of the fragrance microcapsules (size/volume distribution calculations) was based on a SEM analysis (scanning electron microscopy; JSM 6060 LV, Jeol, Japan) and subsequent image analysis (500 measurements; ImageJ software) (ImageJ, n.d.). The characterization of the surface properties of the coated prints was performed by atomic force microscopy (AFM, VeeCO di CP II, Digital Instruments, USA) and scanning probe microscopy software (SPIP, Denmark). For the analysis of the surface roughness properties of the coated samples the standard surface roughness parameter was used (Root-Mean-Square roughness $-\mathrm{S}_{\mathrm{q}}$ ). The optical properties, i.e. the print gloss of the coated prints was measured using the Elcometer 407 Statistical Glossmeter (X-Rite, USA) in accordance with ASTM D523-89 standard (ASTM D523-89, 1999).

\section{RESULTS}

Figure 1a shows the morphology of the fragranced microcapsules in water suspension, which were used in the coating process in combination with the water-based varnish. The fragrance microcapsules used had a particularly regular, spherical shape and a smooth surface of the shell.

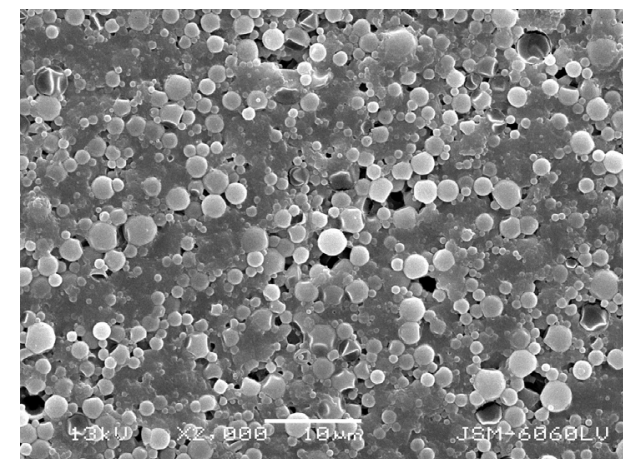

a.

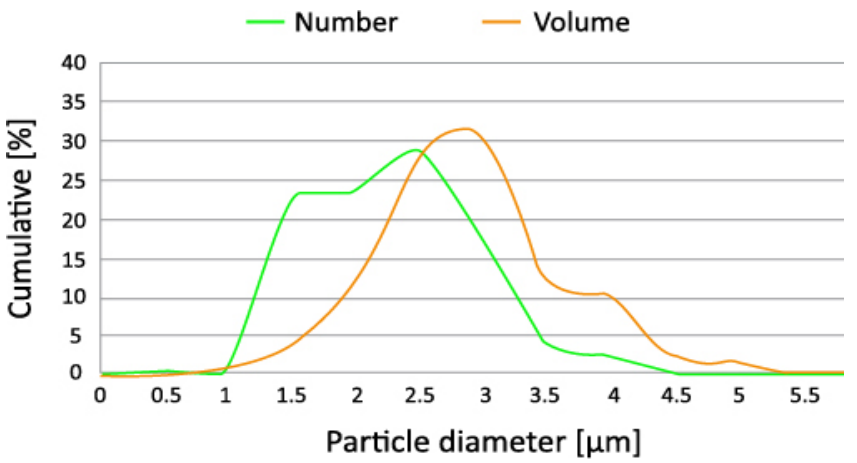

b.

Figure 1: Morphology of fragrance microcapsules in water suspension (a) (SEM; 1.000x magnification) and their size and volume distributions (b)

As Figure $1 b$ shows, the sizes of the fragrance microcapsules are relatively uniform. The distribution of microcapsules diameter sizes was relatively narrow, positively skewed (green curve, Figure $1 \mathrm{~b}$ ), with the vast majority of the microcapsules studied having diameter sizes between 1 and $3 \mu \mathrm{m}$ (92.08\%). The mean diameter size of the sampled fragrant microcapsules is $2.08 \mu \mathrm{m}$ (standard deviation $0.63 \mu \mathrm{m}$ ), while the minimum and maximum diameter sizes are $1.06 \mu \mathrm{m}$ and $4.60 \mu \mathrm{m}$ respectively. The volume distribution of the microcapsules (orange curve, Figure 1b) was nearly symmetrical (normal distribution), with $17.62 \%$ of 
all sampled microcapsules (with diameters between 2.5 and $3 \mu \mathrm{m}$ ) representing $30.36 \%$ of the total volume of the microcapsules. No agglomeration of the microcapsules was observed.

Table 1 shows the results of the surface roughness characteristics of the samples (Root-Mean-Square roughness $-S_{q}$ ) for a solid tone patch (only printed, uncoated), a coated sample with the only varnish without microcapsules (0\%), a coated sample with varnish and fragrant microcapsules in the mass concentration of $1 \%$, and a coated sample with the varnish and microcapsules in the mass concentration of $7 \%$. Figure 2 shows 3D renderings of the AFM data for the same four sample groups.

Table 1: Root-Mean-Square surface roughness values of the tested samples

\begin{tabular}{|c|c|c|c|c|}
\hline Sample & Solid tone & $0 \%$ & $1 \%$ & $7 \%$ \\
\hline $\mathrm{S}_{\mathrm{q}}[\mathrm{nm}]$ & $56.21 \pm 3.49$ & $19.40 \pm 5.20$ & $22.70 \pm 6.23$ & $53.06 \pm 7.15$ \\
\hline
\end{tabular}

From the data presented, it can be seen that only the printed sample (solid tone patch) has the highest surface roughness $\left(\mathrm{S}_{\mathrm{q}}\right)$ compared to other samples (Table 1 and Figure $2 \mathrm{a}$ ). The coating process without fragranced microcapsules drastically reduced the value of the surface roughness (to $19.40 \mathrm{~nm}$ ) and enabled a very uniform and flat surface structure (Figure $2 b$ ). The subsequent addition and increase of the mass concentrations of the fragrant microcapsules in the varnish coating layer ( $1 \%$ and $7 \%$ ) resulted in a significant increase in the surface roughness values $\left(\mathrm{S}_{\mathrm{q}}\right)$, Table 1 . Higher concentrations of the fragrant microcapsules in the coating layer caused more pronounced changes in the surfaces of the coated samples, which resulted in the generation of the numerous new peaks (Figures $2 \mathrm{c}$ and $2 \mathrm{~d}$ ).

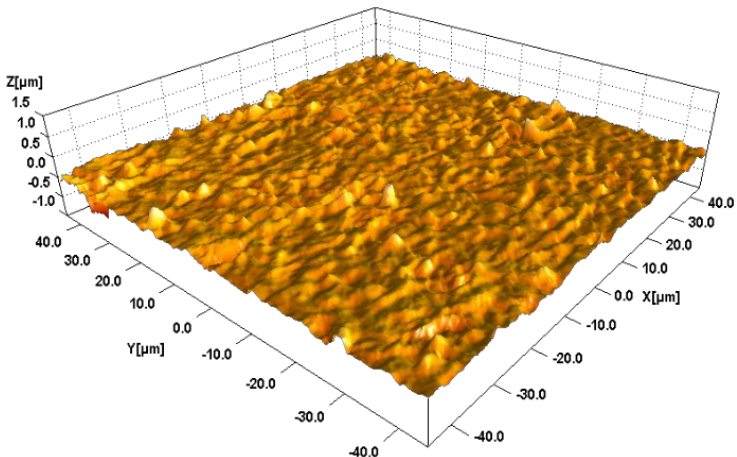

a.

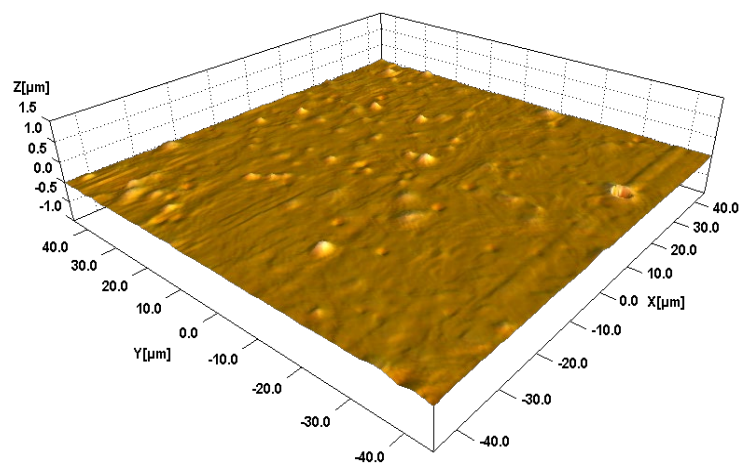

C.

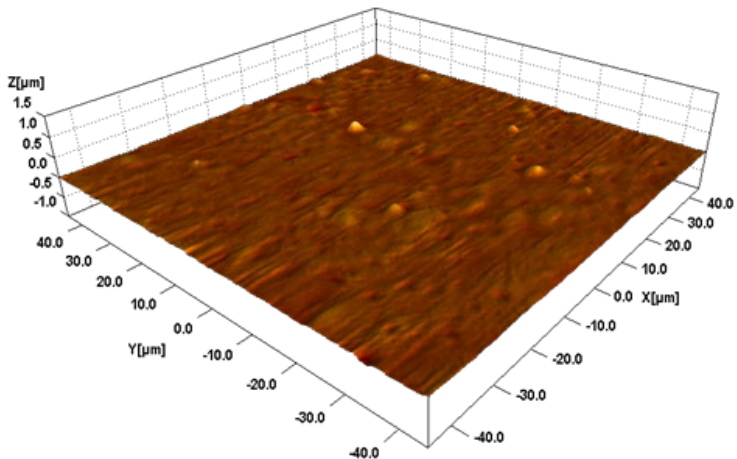

b.

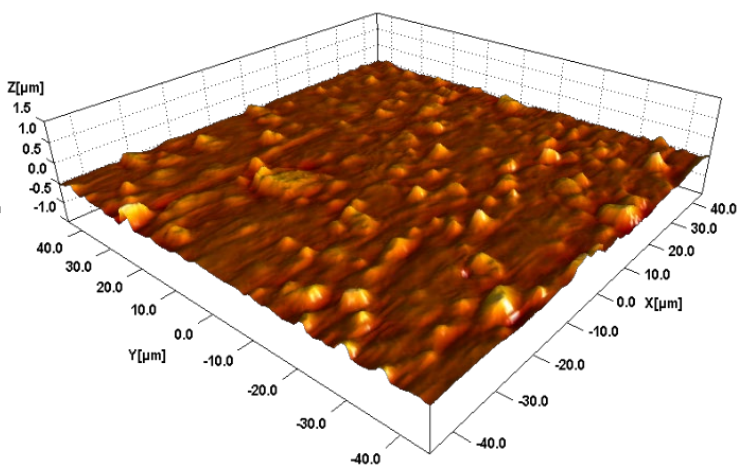

d.

Figure 2: 3D renderings of the acquired AFM data: (a) only printed sample, (b) $0 \%$ sample, (c) $1 \%$ sample, (d) $7 \%$ sample (AFM; $90 \times 90 \mu \mathrm{m})$

The use of the fragrant microcapsules not only increases the value of the final printed product, but also changes the basic print quality properties. Figure 3 shows the measured print gloss values of the tested samples. It can be seen that the sample printed without varnish (cyan solid tone patch) has the lowest print gloss value. The coating applied only with the varnish enabled the highest print gloss value. The addition of fragrant microcapsules, however, led to the generation of many surface irregularities, which affected the reflective properties of the samples, i.e. reduced the print gloss values. With increasing mass concentration 
of the fragrant microcapsules (from $1 \%$ to $7 \%$ ), the print gloss decreased, which is consistent with the previously analyzed surface roughness data.

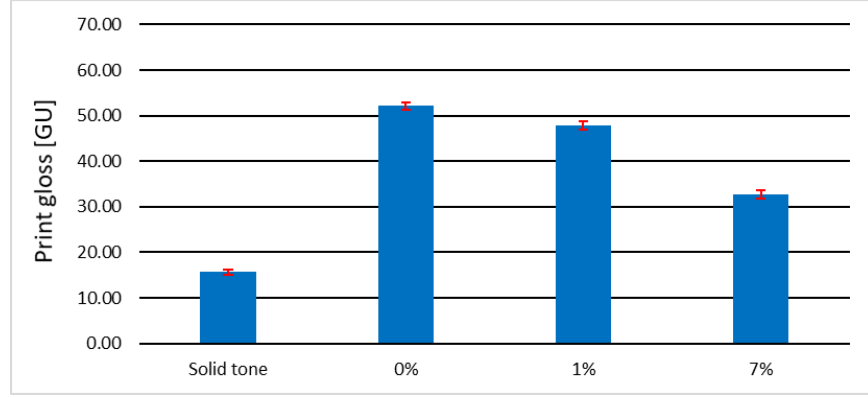

Figure 3: Print gloss data of the analyzed samples $\left(60^{\circ}\right.$ angle)

\section{CONCLUSIONS}

The fragrance microcapsules used in the coating process of the prints had a particularly regular, spherical shape and a smooth surface of the shell. Their diameter sizes were relatively uniform, resulting in a relatively narrow diameter size distribution. The volume distribution of the microcapsules was almost symmetrical, while no agglomeration of the microcapsules was observed.

From the AFM and print gloss analyses presented, it can be concluded that the coating process performed with only varnish, without the fragrant microcapsules, resulted in a uniform, non-porous surface structure with only a few isolated peaks. The resulting surface was much smoother (lower surface roughness value) than the reference sample (only printed solid cyan tone), which in turn enabled the highest print gloss. The use of fragrant microcapsules in the coating process resulted in rougher surfaces with more irregularities, changing the original flat surface of the only coated sample without fragrant microcapsules. The higher concentration of the fragrant microcapsules in the coating layer (7\%) resulted in a higher surface irregularity of the surface, resulting in a significant increase in the surface roughness value $\left(\mathrm{S}_{q}\right)$ and a decrease in print gloss.

\section{ACKNOWLEDGMENTS}

This research was supported by the Ministry of Education, Science and Technological Development through project no. 451-03-68/2020-14/200156: "Innovative scientific and artistic research from the FTS (activity) domain", and by Cinkarna Celje, Slovenia, which provided materials for the experiment.

\section{REFERENCES}

[1] American Inks and Coatings, URL: http://www.americaninks.com/files/AIC\%20pH\%20Technical\%20Bulletin.pdf (last request: 2020-1017).

[2] American Society for Testing and Materials: ASTM D523-89. "Standard test method for specular gloss", American Society for Testing and Materials, 1999. doi: 10.1520/D0523-14R18.

[3] Goetzendorf-Grabowska, B., Krolikowska, H., Gadzinowski, M.: "Polymer Microspheres as Carriers of Antibacterial Properties of Textiles: A preliminary Study", Fibres \& Textiles in Eastern Europe 12 (4), 62-64, 2004.

[4] Goetzendorf-Grabowska, B., Królikowska, H., Bąk P., Gadzinovski, M., Brycki, B., Szwajca, A.: "Triclosan Encapsulated in Poli (L,L-lactide) as a Carrier of Antibacterial Properties of Textiles", Fibres \& Textiles in Eastern Europe 16 (3), 102-107, 2008.

[5] Gosh., K.: "Functional coatings by Polymer Microencapsulation", (Wiley-VCH, Weinheim, 2006.), pages $3 ; 153 ; 177 ; 235$.

[6] ImageJ: "Download", URL: https://imagej.nih.gov/ij/download.html (last request: 2019-08-14).

[7] Milošević, R., Kašiković, N., Cigula, T., Stanković Elesini U., Urbas, R.: "The characterization of microcapsules printed by screen printing and coating technology", Journal of Graphic Engineering and Design 8 (1), 45-56, 2017. doi: 10.24867/JGED-2017-1-045. 
[8] Milošević, R.: "Characterization of coated prints with microcapsules", PhD Thesis, Department of Graphic Engineering and Design, Faculty of Technical Sciences, University of Novi Sad, Serbia, 2019.

[9] Rodrigues, S., Martins, I., Fernandes, I., Gomes, P., Mata, V., Barreiro, M., Rodrigues, A.: "Scentfashion ${ }^{\circledR}$ : Microencapsulated perfumes for textile application", Chemical Engineering Journal 149 (1-3), 463-472, 2009. doi: 10.1016/j.cej.2009.02.021.

[10] Šumiga, B.: "Informational approaches in the design of chemical microencapsulation processes", PhD thesis, Faculty of Natural Sciences and Engineering, University of Ljubljana, Slovenia, 2013.

[11] Urbas, R., Milošević, R., Kašiković, N., Pavlović, Ž., Stankovič Elesini, U.: “Microcapsules application in graphic arts industry: a review on the state-of-the-art", Iranian Polymer Journal 26 (7), 541-561, 2017. doi: 10.1007/s13726-017-0541-1.

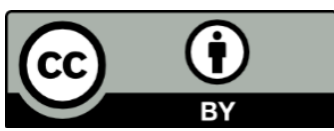

(C) 2020 Authors. Published by the University of Novi Sad, Faculty of Technical Sciences, Department of Graphic Engineering and Design. This article is an open access article distributed under the terms and conditions of the Creative Commons Attribution license 3.0 Serbia (http://creativecommons.org/licenses/by/3.0/rs/). 